\title{
Observer Design for Downsized Gasoline Engine Control Using 1D Engine Simulation
}

\author{
A. Albrecht' ${ }^{1}$ V. Knop ${ }^{1}$, G. Corde', L. Simonet ${ }^{1}$ and M. Castagné ${ }^{1}$ \\ 1 Institut français du pétrole, 1 et 4, avenue de Bois-Préau, 92852 Rueil-Malmaison Cedex - France \\ e-mail: antoine.albrech+@ifp.fr - vincent.knop@ifp.fr - gilles.corde@ifp.fr - laurent.simonet@ifp.fr - michel.castagne@ifp.fr
}

\begin{abstract}
Résumé - Conception d'un observateur pour le contrôle d'un moteur écosuralimenté à partir d'un simulateur 1D moteur - Cette étude présente la mise au point du modèle 1D d'un moteur 2.01 à injection directe essence équipé d'un turbocompresseur avec turbine double entrée et d'un double déphaseur d'arbre à cames et son utilisation dans la conception du contrôle moteur. Le moteur virtuel est employé pour le développement d'un observateur de masses enfermées dans les cylindres dont l'estimation constitue un enjeu majeur pour ce type de moteur à cause des forts effets de balayage dans la chambre de combustion. Après avoir réglé le modèle moteur grâce à des résultats de banc d'essais moteur, celui-ci permet de reproduire fidèlement les phénomènes de première importance pour le contrôle moteur tels que la modification du remplissage et de la combustion par le croisement de soupapes. Ces performances permettent de s'appuyer fortement sur le moteur virtuel pour développer plus efficacement l'observateur/contrôleur de masses enfermées et réaliser un premier niveau de validation. L'objectif de cet article est de démontrer que la simulation système moteur est un élément incontournable pour la chaine de conception du contrôle moteur, du développement à la validation dans un environnement temps réel.
\end{abstract}

\footnotetext{
Abstract - Observer Design for Downsized Gasoline Engine Control Using $1 D$ Engine Simulation This study presents the use of a $1 D$ engine model for the control design of a twin-scroll turbocharged gasoline direct injection $2.0 \mathrm{l}$ it engine with twin camphaser. This virtual engine is used for the development of the in-cylinder mass observer which is a crucial issue for the control of such an engine because of the large scavenging effects. After the model calibration process based on bench results, the virtual engine reproduces with accuracy the major behaviour such as valve overlap effects on cylinder filling and combustion which are an important feature for engine control with such advanced technology. Finally, thanks to the engine model contribution, the in-cylinder mass controller/observer design can be made easier and is validated off-line at a first stage. The goal of the paper is to demonstrate the relevancy of using $1 D$ engine simulation as a support tool during all the steps of the engine control development process from design to real-time validation.
} 


\section{ABBREVIATIONS}

$\begin{array}{ll}\text { AFR } & \text { Air Fuel Ratio } \\ \text { ATDC / BTDC } & \text { After / Before Top Dead Center } \\ \text { BGR } & \text { Burnt Gas Ratio } \\ \text { BMEP } & \text { Brake Mean Effective Pressure } \\ \text { CA } & \text { Crank Angle } \\ \text { EVC / IVC } & \text { Exhaust / Intake Valve Closing } \\ \text { EVO / IVO } & \text { Exhaust / Intake Valve Opening } \\ \text { IMEP } & \text { Indicated Mean Effective Pressure } \\ \text { MBT } & \text { Maximum Brake Torque } \\ \text { Ne } & \text { Engine Speed } \\ \text { SI } & \text { Spark Ignition } \\ \text { VVT } & \text { Variable Valve Timing } \\ \text { atm } & \text { Atmosphere } \\ \text { man } & \text { Manifold } \\ \text { in } & \text { Intake } \\ \text { super } & \text { Supercharging. }\end{array}$

\section{INTRODUCTION}

Strongly downsizing gasoline engines is one of the most promising means for reduction of consumption and $\mathrm{CO}_{2}$ emission. Based at IFP on an innovative combination of homogeneous direct injection, turbocharging and variable valve timing $[1,2]$, this approach allows reduction of burnt gas residuals thanks to a scavenging effect. Thus, with increasing knock resistance, the engine displacement can be reduced and the engine achieves higher efficiency at low and partial loads while maintaining attractive power output at full load.

In order to fully benefit from such an advanced technology, dedicated engine control management is of prime importance. It must ensure that the engine is running in an optimized mode during all the operating conditions, especially during load transients, in order to reduce the effects of turbo lag. Therefore, the Air Path of the torque structure must be redesigned; especially to control the engine behaviour by manipulating the masses of air and burnt gas trapped in the cylinder after intake valve closing (IVC).

To reach this objective, models of engines running with a timescale of the order of the crank angle (high frequency) are necessary for the development of the engine control design. This allows access to variables which are unavailable with low frequency models, such as a mean value engine model, and difficult to estimate from experimental results. Moreover, it cuts down the number of expensive test bench experiments required.

In the first part of this paper, the engine model development is described. The AMESim platform and the IFPENGINE library are introduced. The engine configuration and the associated engine model are then presented. The specific modelling approach for the most complex components such as the twin-scroll turbine or combustion chamber are detailed.

Afterwards, a methodical and complete calibration of the virtual engine is achieved for steady state and transient operations with respect to test bed results. The way the engine model represents valve overlap effects on cylinder filling at various loads and engine speed is presented.

Finally, the validated model is used as a virtual engine in order to develop an in-cylinder mass observer for engine control, allowing access to relevant internal variables such as air and residual gas masses trapped in the cylinder. The mass observer obtained is presented and validated under transient operating conditions.

\section{ENGINE MODELLING APPROACH}

\subsection{Engine System Modelling}

In general, three types of modelling levels are used for engine simulation. The most accurate modelling approach is the CFD 2D/3D simulation. It is dedicated to combustion chamber studies and allows the local phenomenon in the cylinder such as turbulent combustion and chemical kinetics to be captured in detail. The characteristic timescale of CFD simulation is to the order of the turbulent timescale. At the present time, the CPU time of such a simulation only allows a few engine cycles to be run. The simplest modelling approach consists in representing the engine with operating condition look-up tables. This level allows CPU time lower than real time to be achieved and is used to connect the engine with the complete powertrain and to run standard driving cycles with a vehicle simulator. The characteristic timescale of vehicle simulation is of the order of 0.1 second. Intermediate between these two approaches, the third modelling level is the engine system modelling. This approach involves phenomenological or empirical models and allows the complete engine to be represented with a characteristic timescale to the order of 0.1 crankshaft degree. Thanks to dedicated code optimization to limit the CPU time cost, the engine system model allows the behaviour of the engine during transients of the driving cycle to be reproduced accurately while reaching real time in certain conditions [3, 4]. Therefore, this approach is especially adapted to be used as a support tool for engine control design from control development to hardware-in-the-loop validation $[5,6]$.

\subsection{IFP-ENGINE Library Overview}

The IFP-ENGINE library allows a complete virtual engine to be computed with a characteristic timescale in the order of that of the crankshaft. All the necessary components to build an accurate model for current engine technology are proposed, e.g. various turbochargers and gasoline direct 
injection but also Diesel engines with EGR loop (Fig. 1). Thanks to specific developments for turbochargers and combustion, advanced models are available in order to reproduce the complex physical phenomena which take place in an internal combustion engine [7].

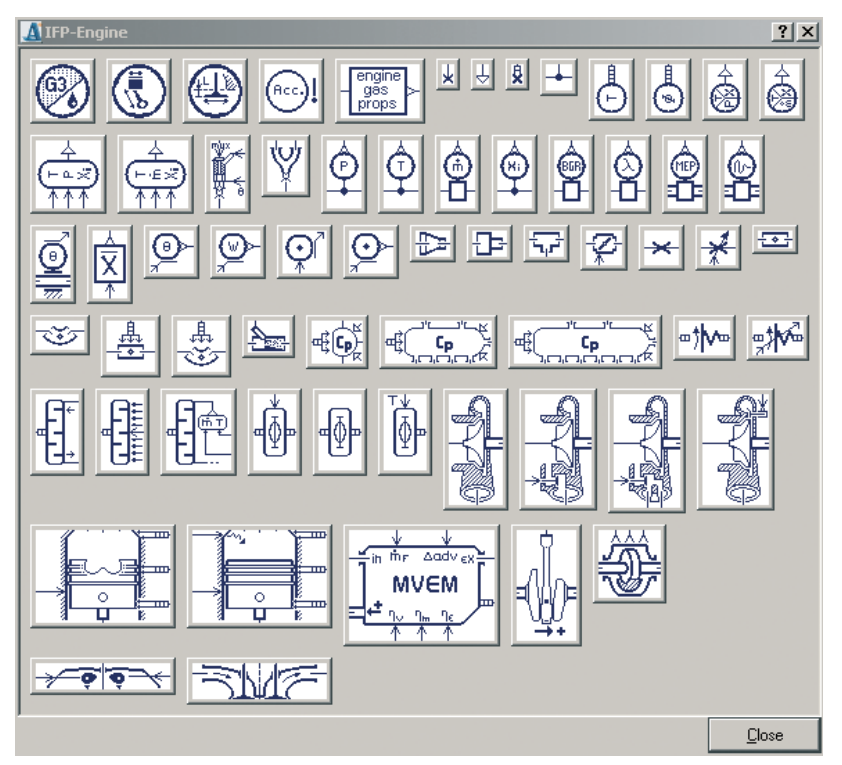

Figure 1

IFP-ENGINE library.

\subsubsection{AMESim Environment}

The IFP-ENGINE library has been developed in the AMESim environment edited by IMAGINE which is an open numerical platform for the modelling and the simulation of dynamic systems inspired by the Bond Graph approach [8]. The numerical solver automatically and dynamically selects the best-adapted calculation method among 17 available algorithms.

\subsubsection{Gas Dynamic Modelling}

The computed gas consists of 3 species: fresh air, vaporized fuel and burnt gas. This thermodynamic assumption has been identified as sufficient for engine performance results. Main relevant orifice and pipe elements are available such as air throttle, valve, straight and kneed ducts. Friction and inertial effects are taken into account. Heat exchanges are modelled for each element and specific heat exchanger models are also available with air and water cooling systems.

\subsubsection{Cylinder Head Modelling}

An ideal camshaft system is proposed. Inlet and exhaust valves are piloted by valve lift trajectories and cross section characteristics. A more physical approach, to take into account mechanical or hydraulic aspects, is available using relevant complementary AMESim libraries.

\subsubsection{Engine Combustion Modelling}

Original developments have been implemented for engine combustion chamber modelling. Two efficient phenomenological models are available to represent gasoline and Diesel combustion. The gasoline combustion model is based on an adaptation of the Extended Coherent Flame Model [7] and is adapted to reproduce the homogeneous flame propagation encountered in spark ignition combustion. The Diesel combustion model has been developed from Chmela's and Barba's approaches $[9,10]$ extended to multi-pulse injection, auto-ignition delay and EGR effect correction [11]. In addition, a mapped combustion model using experimental or $3 \mathrm{D}$ numerical combustion results is also available. Cylinder wall thermal exchanges can be taken into account following the Eichelberg, Annand or Woschni models. Injection models allow the fuel mass injection rate to be controlled using maps or algebraic functions. The fuel can be injected in gaseous or in liquid phase. The Direct or Port Fuel Injection vaporization process is governed by a characteristic timescale.

\subsubsection{Turbocharger Modelling}

All the elements needed to build most of the turbocharger technologies are proposed. The modelling approach is based on turbocharger manufacturers' maps with additional specific developments such as for twin-scroll turbine or variable nozzle turbine models. To feed these models with appropriate numerical data, a dedicated tool has been developed to process the turbo maps before use.

\subsubsection{Mechanical Transmission Modelling}

The IFP-ENGINE library allows mechanical transmission aspects such as the connecting rod or the crankshaft to be represented without accounting for inertia. A more complex modelling is easily possible using the Powertrain AMESim library.

\section{ENGINE MODEL DEVELOPMENT}

\subsection{Engine Set-Up}

Downsizing means replacing a given engine with one of smaller displacement volume without loss of performance or efficiency. This is usually achieved by supercharging using turbochargers or mechanically driven compressors. The goal of the study is to replace a naturally aspirated 3.0-liter SI engine by a turbocharged 2.0-liter engine, preserving maximum engine performance and transient behaviour by reducing turbo lag effect. The IFP downsizing approach aims at achieving this by combining turbocharging, homogeneous 
direct injection and variable valve timing (VVT) on both camshafts. Moreover, a twin-scroll turbine is used to maximize kinetic energy recovery through the strong pulsating exhaust pressures which are accentuated by small exhaust manifolds [12]. Recent experimental results seem to show that the single-scroll turbine also represents an efficient configuration [13].

The main characteristics of the engine are:

- Renault F4R engine block

- Renault F5R cylinder head

- Four cylinder SI engine

- Waste-gate turbocharger with twin-scroll turbine

- Homogeneous direct gasoline injection

- Variable valve timing on intake and exhaust camshafts (valve lift invariable)

- Stroke: $93 \mathrm{~mm}$

- Bore: $82.7 \mathrm{~mm}$

- Compression ratio: 10.5:1

A scheme of the engine set up is presented in Figure 2.

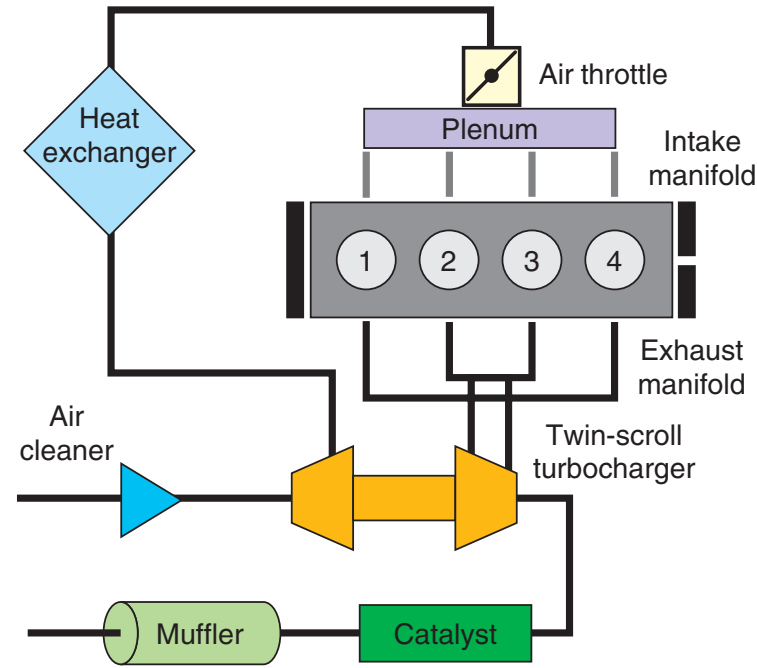

Figure 2

Engine set-up diagram

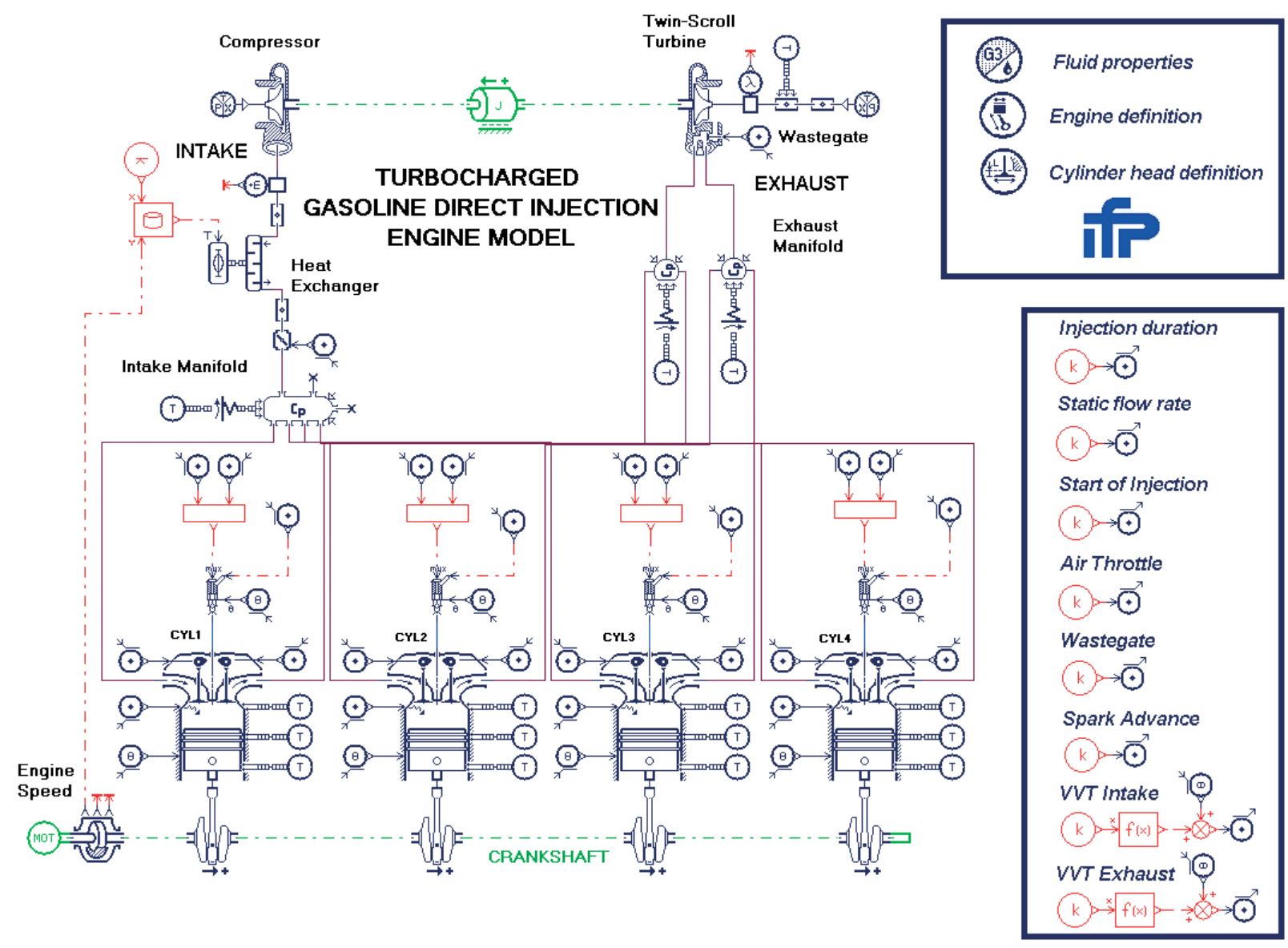

Figure 3

Engine model diagram. 


\subsection{Turbocharged GDI Engine Model}

\subsubsection{General Description}

The goal of engine simulation is to supply the relevant model for the specific application. User expectations have to be accurately understood in order to achieve the optimum tradeoff between physical description and calculation time cost. Engine control design has strong time cost constraints. It needs to consider a large number of engine operating points and is oriented towards a real time environment.

In order to build an engine model which runs fast enough to be an efficient tool for engine control development, the engine model physical description level has been minimized to focus its performances on control goals such as cylinder filling and instantaneous relative air/fuel ratio (AFR). The engine model diagram is presented in Figure 3. This model runs at 25 times real time with the variable time step solver and a $3 \mathrm{GHz}$ PC. The fixed time step solver can be used to reduce the CPU time, especially in order to build the real time engine model.

\subsubsection{Air Path Representation}

Air path includes a compressor, pipes, a heat exchanger, a throttle and an intake manifold. All these elements are represented by dedicated submodels. The necessary compromise between the engine model accuracy and the simulation time cost has a major impact on the complexity of the phenomena taken into account in this part of the engine model. As representation of high frequency pulses in the intake manifold is very time consuming, a trade-off between accuracy of instantaneous pressure fluctuations and time consumption needs to be found. This is done by comparing different levels of manifold modelling detail. For our purpose, the best compromise is the approach that allows the lowest time consumption while limiting the effect on neighboring elements of neglecting in-manifold phenomena.

\subsubsection{Combustion Chamber Modelling}

The combustion chamber is connected to the air path through the cylinder head which acts according to valve lift laws and a permeability behaviour model derived from experimental characterization. The fuel is directly injected in the chamber and its quantity is governed by injection duration. In the cylinder wall, heat losses are modelled using Woschni's approach with three independent temperatures for the cylinder head, the piston and the liner. The combustion heat release is generated with a transient Wiebe's law approach using mapped coefficients. The maps are derived from an automatic combustion fitting process, analyzing experimental cylinder pressure data. The coefficients vary with volumetric efficiency (in-cylinder air mass) and burnt gas ratio (BGR). As exhaust relative air/fuel ratio is assumed to be sufficiently close to 1 , in-cylinder air/fuel ratio is not relevant as a parameter for combustion heat rate mapping.

\subsubsection{Twin-Scroll Turbocharger Approach}

A specific twin-scroll turbocharger approach has been developed. Before the runs, it allows polynomial forms based on physical model to the turbocharger manufacturer maps to be fitted in order to obtain an extended operating range for compressor and turbine. During the runs, these polynomial forms are coupled with dedicated physical treatment. For the compressor, the boundary behaviours such as surge effect and choke area are taken into account. For the twin-scroll turbine, additional specific developments have been implemented in order to take into account divided turbine housing. The waste-gate and the leakage sections are modelled using the Barré St Venant's approach. The turbine backflow is also taken into account.

\subsubsection{Variable Valve Timing Management}

For the calculation of steady-state operating conditions, modelling of camshaft angular positioning is sufficient to provide relevant results. When transient engine behaviour is investigated, a more complex model accounting for the delay in positioning is needed. This should be basically done by introducing a delay correlated to engine speed thanks to experimental data. This aspect has not been modelled for the results presented in this paper.

\subsection{Engine Model Calibration and Validation}

Before its use for engine control design, the engine model has to be calibrated and validated. Most of the model calibration parameters are physical parameters. This work is achieved by comparing computation results with testbed measurements. Experimental acquisitions provide data on a wide set of operating points. Numerous mean engine values and instantaneous pressures (in-cylinder, intake, exhaust) are available in order to calibrate and validate the model.

\subsubsection{Steady State Operating Condition Calibration and Validation}

At first, the engine model is tested on steady state points. Some relevant results have been extracted as examples for this paper. Three experimental campaigns have been chosen: a load variation at fixed engine speed (4000 rpm), an engine speed variation at fixed load (9 bar IMEP) and a valve timing variation at $1200 \mathrm{rpm} / 9$ bar IMEP. For all tests, the bench set points are strictly applied to the engine model. The modelling parameters are the same for all the simulations.

\section{Engine Model Calibration}

The model is calibrated using 12 steady state load points at $4000 \mathrm{rpm}$ from 1.6 to 19 bar of BMEP. The associated intake 
pressure varies from 0.465 to 2.32 bar. The valve timing is the optimal one determined during test bed experimentation which is mainly a small valve overlap configuration. For each operating point, the engine model results are compared to experimental mean and instantaneous values. Table 1 gives a complete comparison of mean engine values between model and experiment for the full load point. Figures 4 to 6 demonstrate the calibration accuracy by showing the instantaneous agreement of the engine model with bench data for intake, exhaust and in-cylinder pressures. Submitted to $\mathrm{CPU}$ time cost constraints, the numerical model gives satisfactory behaviour for engine control goals and is also able to take into account finer physical phenomena with a more detailed engine model.

TABLE 1

Model/bench mean results at full load IMEP 20 bar and $4000 \mathrm{rpm}$

\begin{tabular}{l|c|c|c|c}
\hline & & Model & Bench & $\begin{array}{c}\text { Relative } \\
\text { deviation }\end{array}$ \\
\hline IMEP & bar & 19.68 & 19.86 & $-0.9 \%$ \\
Mass air flow & $\mathrm{kg} / \mathrm{h}$ & 426.2 & 457.8 & $-6.9 \%$ \\
Relative air/fuel ratio (AFR) & - & 0.85 & 0.87 & $-2.3 \%$ \\
Supercharging pressure & $\mathrm{bar}$ & 2.140 & 2.049 & $+4.4 \%$ \\
Intake pressure & $\mathrm{bar}$ & 2.001 & 1.998 & $+0.1 \%$ \\
Intake temperature & ${ }^{\circ} \mathrm{K}$ & 319.2 & 318.5 & $+0.2 \%$ \\
Exhaust pressure (Cyl. 1 \& 4) & $\mathrm{bar}$ & 2.283 & 2.140 & $+6.7 \%$ \\
Exhaust temp. (Cyl. 1 \& 4) & ${ }^{\circ} \mathrm{K}$ & 1203 & 1197 & $+0.5 \%$ \\
Exhaust pressure (Cyl. 2 \& 3) & $\mathrm{bar}$ & 2.199 & 2.042 & $+7.7 \%$ \\
Exhaust temp. (Cyl. 2 \& 3) & ${ }^{\circ} \mathrm{K}$ & 1215 & 1219 & $-0.3 \%$ \\
Downstream turbine pressure & $\mathrm{bar}$ & 1.181 & 1.235 & $-4.4 \%$ \\
Downstream turbine temp. & ${ }^{\circ} \mathrm{K}$ & 1092 & 1115 & $+2.0 \%$ \\
\hline
\end{tabular}

a)Load Variation@ 4000 rpm

Figures 7 to 10 present comparisons of mean engine values between model and bench for the 12 load set points and show a good representativity level of the model.

\section{b) Engine Speed Variation @ 9 bar IMEP}

To test the accuracy of the model with regard to engine speed variation, 4 engine speeds (from 1200 to $4000 \mathrm{rpm}$ ) are investigated for a given load. These reference operating points are a full atmospheric load with intake pressure close to 1 bar and IMEP = 9 bar. The valve timing is the smallest valve overlap possible. As it is a reduced valve overlap configuration, the experimental volumetric efficiency can be directly computed from experimental mass air flow measurement. Figure 11 and Figure 12 gather model results on volumetric efficiency and IMEP at the various engine speeds and compare them to bench data.

\section{c) Valve Timing Variation @ 1200 rpm / 9 bar IMEP}

Finally, the engine model is tested on valve timing variation at partial load (IMEP 9 bar) and low engine speed (1200 rpm) to demonstrate the model accuracy while modifying valve overlap timing and duration.

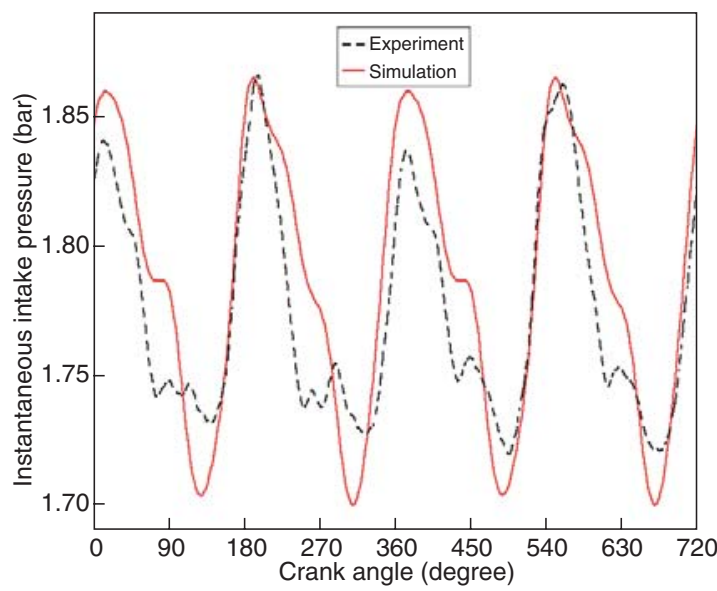

Figure 4

Instantaneous intake pressure model/bench comparison at full load $(\mathrm{BMEP}=19 \mathrm{bar}-4000 \mathrm{rpm})$.

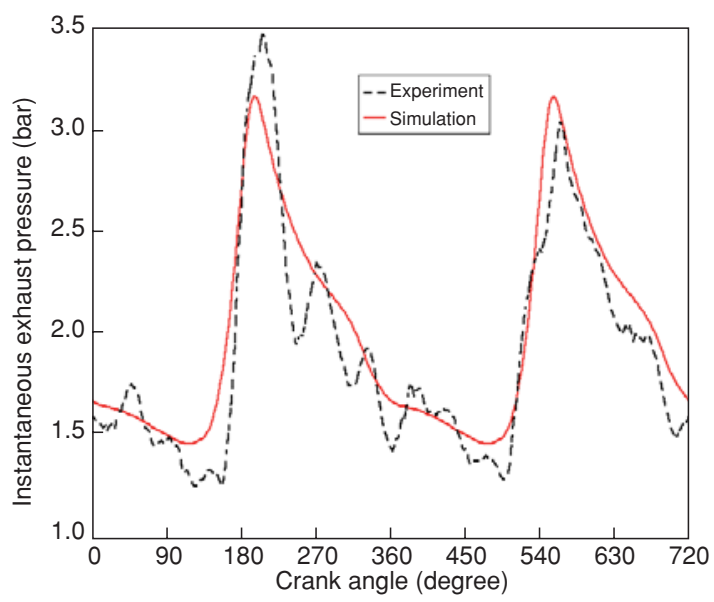

Figure 5

Instantaneous exhaust pressure model/bench comparison at full load (BMEP = 19 bar $-4000 \mathrm{rpm})$.

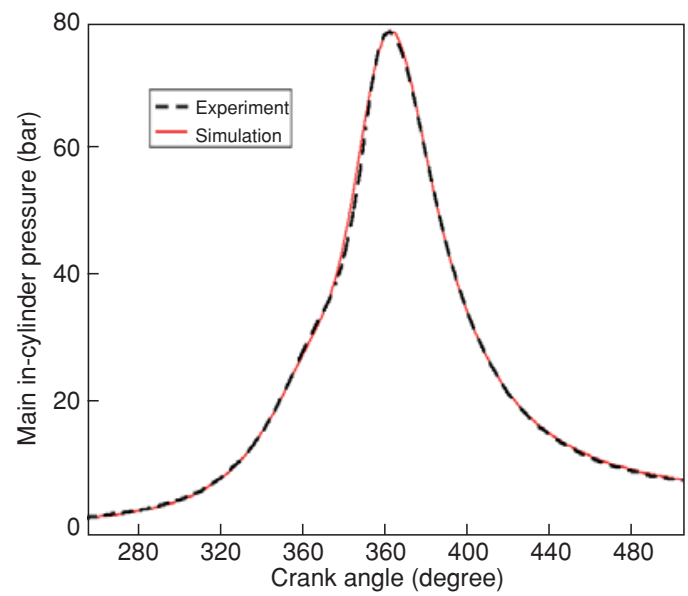

Figure 6

Instantaneous in-cylinder pressure model/bench comparison at full load (BMEP = $19 \mathrm{bar}-4000 \mathrm{rpm})$. 


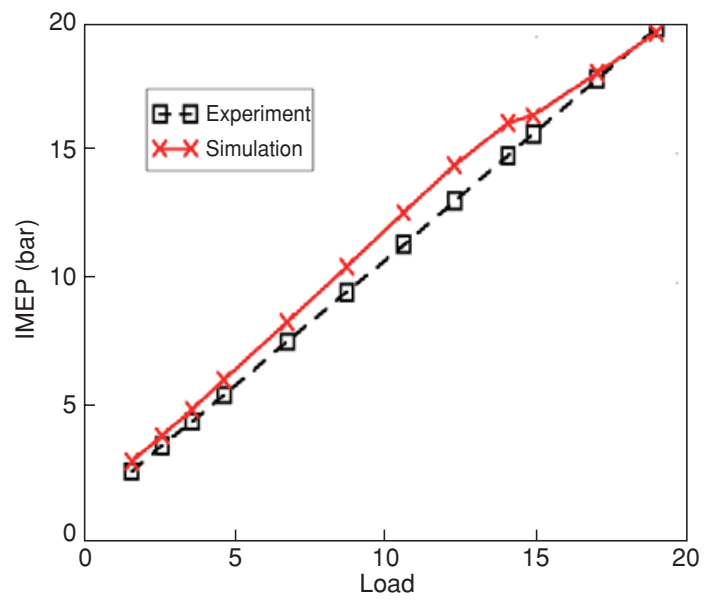

Figure 7

IMEP model/bench comparison vs load set point @ 4000 rpm.

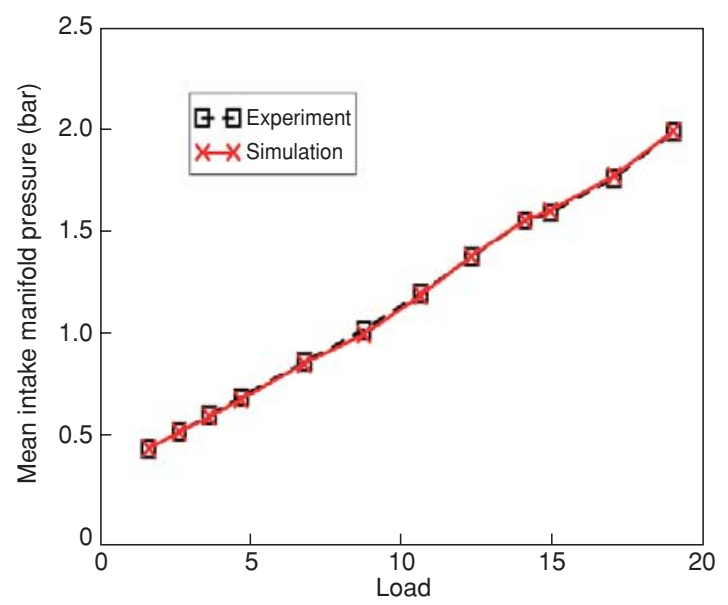

Figure 9

Intake pressure model/bench comparison $v s$ load set point @ 4000 rpm.

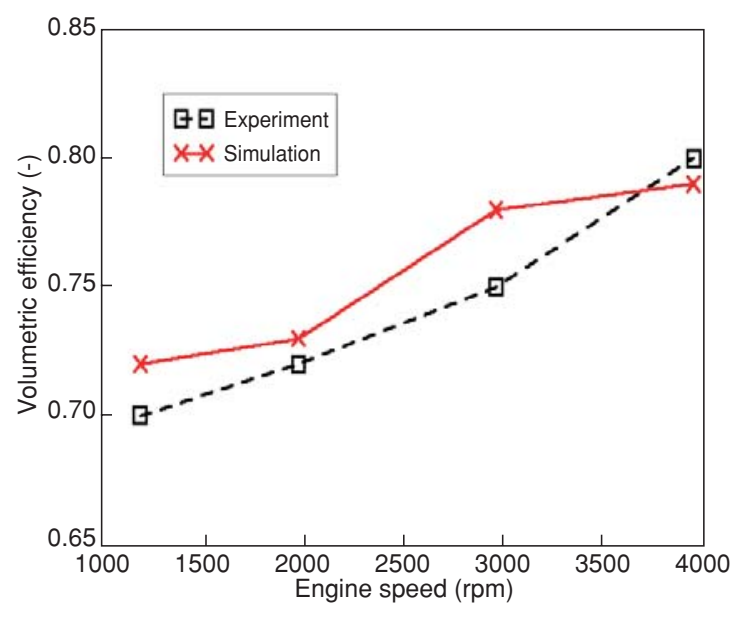

Figure 11

Volumetric efficiency model/bench comparison $v s$ engine speed.

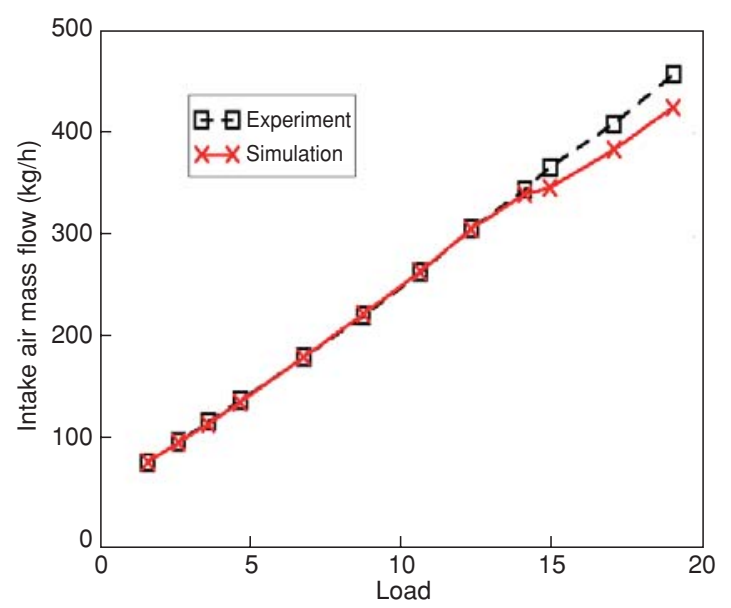

Figure 8

Mass air flow model/bench comparison vs load set point @ 4000 rpm.

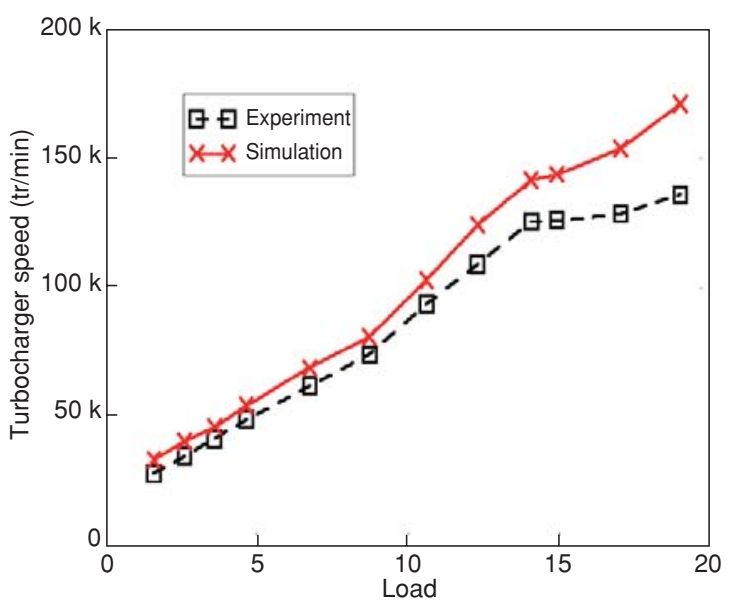

Figure 10

Turbocharger speed model/bench comparison $v s$ load set point @ 4000 rpm.

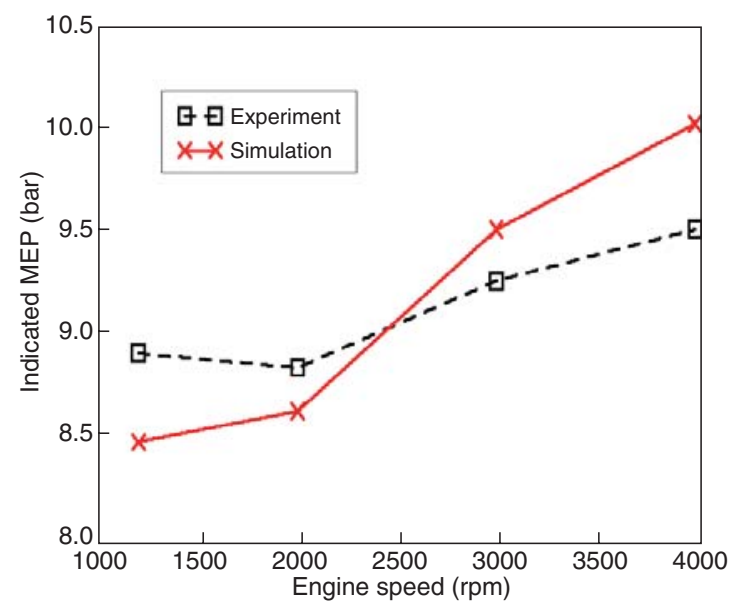

Figure 12

IMEP model/bench comparison $v s$ engine speed. 
Table 2 presents the 9 different valve overlaps tested. For each valve timing, maximum brake torque (MBT) spark advance is chosen and air throttle position is adapted in order to maintain the load.

The experimental optimum is for set point 7. Table 3 presents comparison between model and bench results on characteristic engine mean values for this operating point.

TABLE 2

Valve timing set points for steady state validation

\begin{tabular}{l|c|c|c|c|c|c|c|c|c}
\hline Set point & 1 & 2 & 3 & 4 & 5 & 6 & 7 & 8 & 9 \\
\hline IVO $\left[{ }^{\circ} \mathrm{CA} \mathrm{BTDC}\right]$ & -10 & 30 & 0 & 0 & 30 & 0 & 30 & 0 & 30 \\
\hline EVC $\left[{ }^{\circ} \mathrm{CA} \mathrm{ATDC}\right]$ & -20 & 0 & -10 & 0 & -10 & 10 & 10 & 20 & 20 \\
\hline
\end{tabular}

\section{TABLE 3}

Model/bench mean results at IMEP 9 bar and $1200 \mathrm{rpm}$ (Table 2 - set point 7)

\begin{tabular}{l|c|c|c|c}
\hline & & Model & Bench & $\begin{array}{c}\text { Relative } \\
\text { deviation }\end{array}$ \\
\hline IMEP & $\mathrm{bar}$ & 8.72 & 8.85 & $-1.5 \%$ \\
Mass air flow & $\mathrm{kg} / \mathrm{h}$ & 60.2 & 60.7 & $-0.8 \%$ \\
Relative air/fuel ratio (AFR) & - & 0.997 & 0.999 & $-0.2 \%$ \\
Intake pressure & $\mathrm{bar}$ & 0.972 & 0.973 & $-0.1 \%$ \\
Intake temperature & ${ }^{\circ} \mathrm{K}$ & 312 & 311 & $+0.3 \%$ \\
Exhaust pressure (Cyl. 1 \& 4) & $\mathrm{bar}$ & 1.051 & 1.035 & $+1.5 \%$ \\
Exhaust temp. (Cyl. 1 \& 4) & ${ }^{\circ} \mathrm{K}$ & 908 & 917 & $-1.0 \%$ \\
Exhaust pressure (Cyl. 2 \& 3) & $\mathrm{bar}$ & 1.053 & 1.033 & $+1.9 \%$ \\
Exhaust temp. (Cyl. 2 \& 3) & ${ }^{\circ} \mathrm{K}$ & 933 & 949 & $-1.7 \%$ \\
Downstream turbine pressure & $\mathrm{bar}$ & 1.019 & 1.017 & $+0.2 \%$ \\
Downstream turbine temp. & ${ }^{\circ} \mathrm{K}$ & 855 & 890 & $-3.9 \%$ \\
\hline
\end{tabular}

Since the exhaust pressure does not vary much for these partial load operating points, the intake manifold pressure is one of the main thermodynamic variables which may be influenced by the valve overlap variations. Furthermore, the intake pressure is a crucial information for engine control in volumetric efficiency observer design. Therefore, the model robustness in intake manifold pressure prediction is very important. Figure 13 presents a comparison between model and bench intake pressures for all the set points from Table 2.

With such large valve overlaps at low engine speed and part load, a counter scavenging effect can occur and partially fill the cylinder with burnt gases from the exhaust manifold. As no efficient sensor for in-cylinder mass and composition measurement exists, the engine model is an important tool to evaluate valve timing influence on burnt gas mass trapped after IVC. Figure 14 not only highlights the global rise in burnt gas mass while increasing the valve overlap duration but also emphasizes the importance of valve overlap timing. Finally, Figure 15 shows that in-cylinder pressure from the model fits well with bench data when burnt gas rate varies.

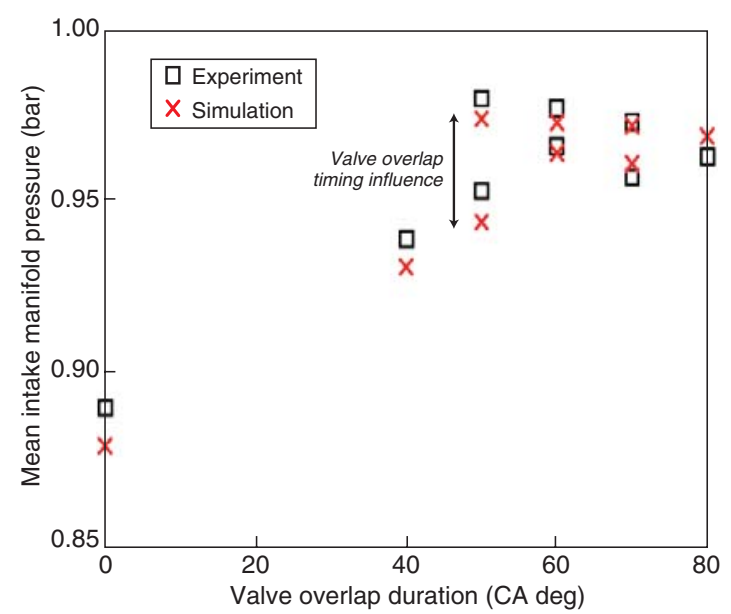

Figure 13

Model/bench intake pressure comparison for operating set points from Table 2 .

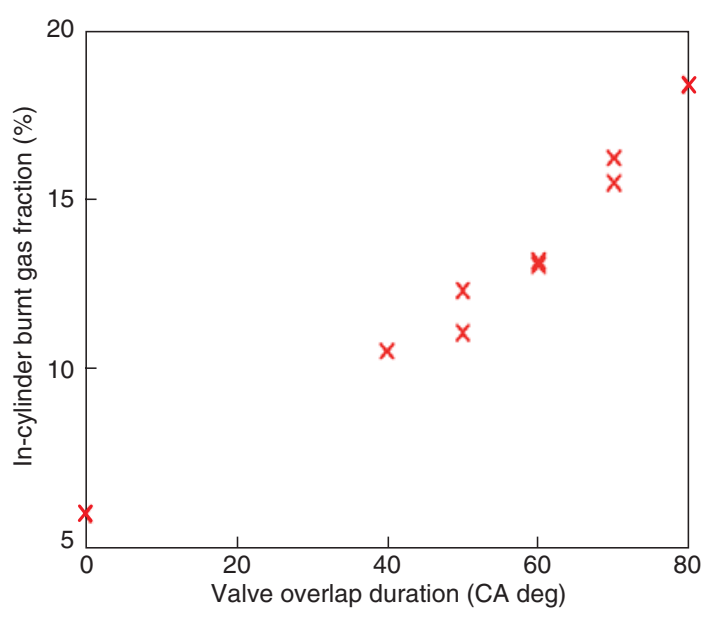

Figure 14

Valve overlap setting effect on in-cylinder burnt gas fraction (simulation results).

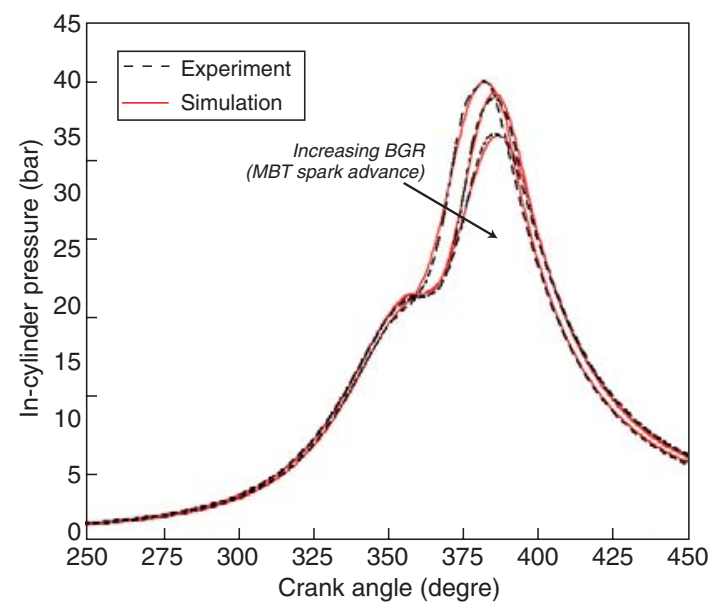

Figure 15

Model/experiment in-cylinder pressure comparison with $\mathrm{BGR}=5,10$ and $15 \%$. 

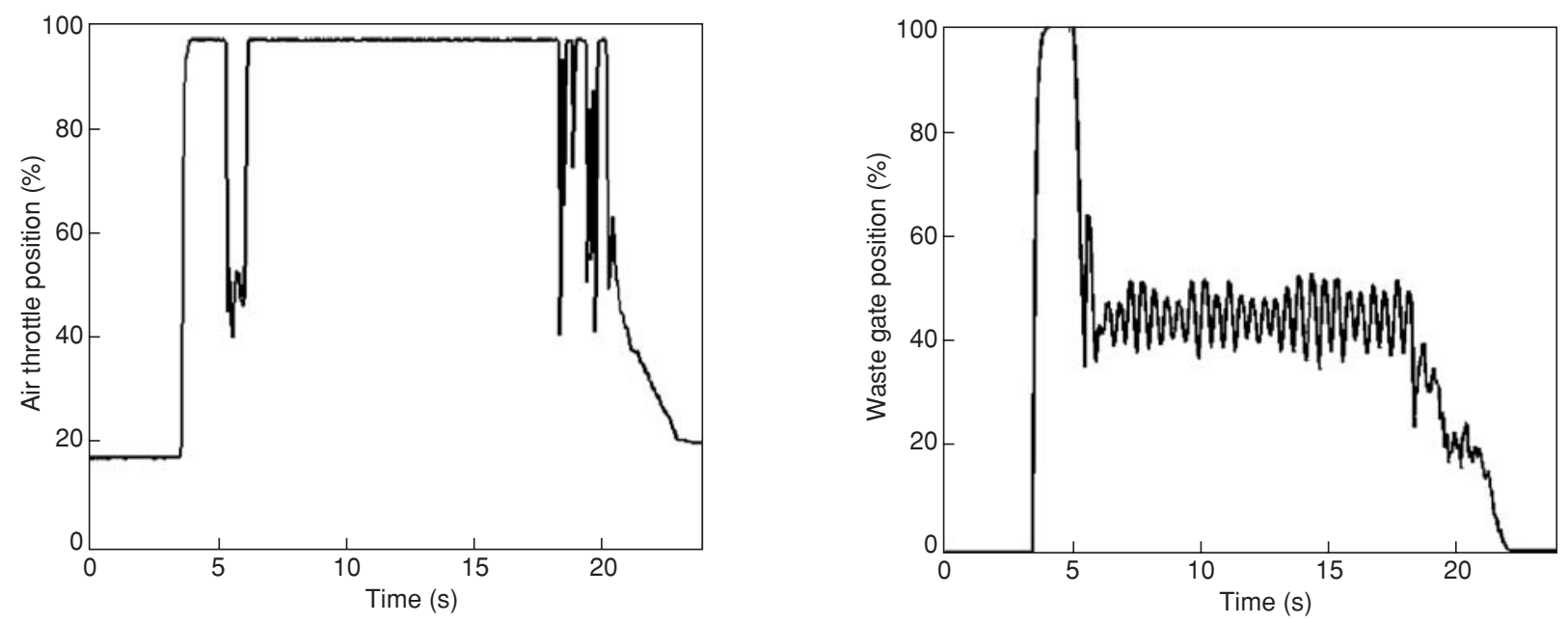

Figure 16

Air throttle and waste gate position vs time during transient load @ 1500 rpm.

\subsubsection{Transient Load Operating Condition Validation}

One of the main engine control goals for turbocharged gasoline direct injection engine is to reduce the turbo lag during transient load. In order to use the engine model over as wide a range as possible the virtual engine has also to be validated under transient operating conditions. As an example, the following results show a comparison between the model and the bench for a $24 \mathrm{~s}$ tip in/tip out transient at $1500 \mathrm{rpm}$. The experimental testbed has been set up with a torque based control piloting the air throttle, the wastegate, the injection duration, the spark advance and the intake and exhaust VVT positions. All the actuator positions are recorded at the bench and then used to replay the testbed. For example, Figure 16 plots air throttle and waste gate position trajectories used to pilot the engine model during the transient. The VVT's were not used as a regulating actuator on this specific testbench and stay at quite fixed positions with a large overlap as shown on Figure 17. The goal of this validation set up is to test the behaviour of the virtual engine when imposing the same inputs as for the bench test. It means that all the actuator targets can be applied to the model with any engine control regulation. This open loop method is a very strict test for the model because any small deviation compared to a real engine test may be emphasised by the absence of engine control.

Figures 18 to 20 present a comparison between simulation and experiment for intake pressures, turbocharger speed and
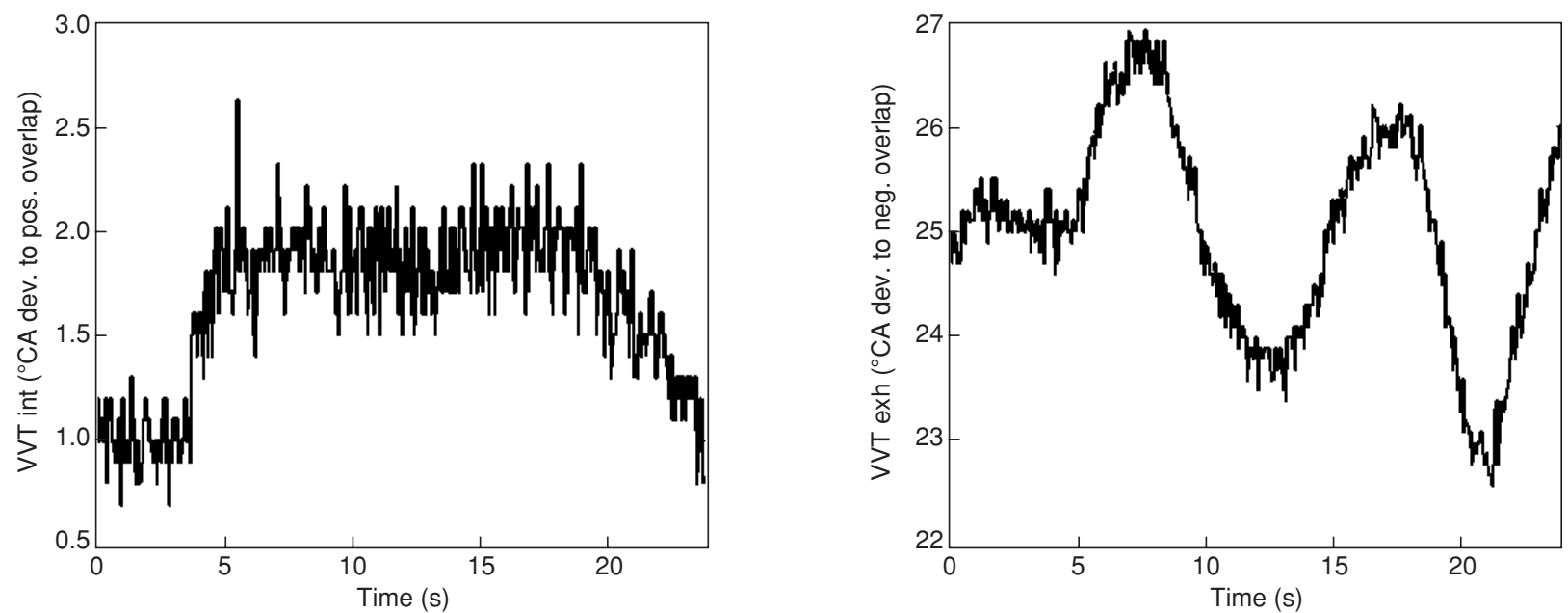

Figure 17

VVT's position vs time during transient load @ 1500 rpm. 


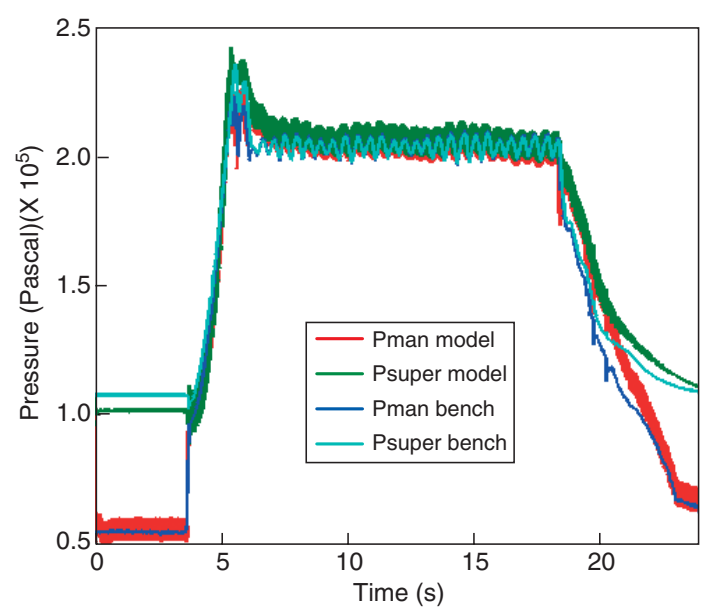

Figure 18

Intake pressure model/bench comparison vs time during transient load@1500 rpm.

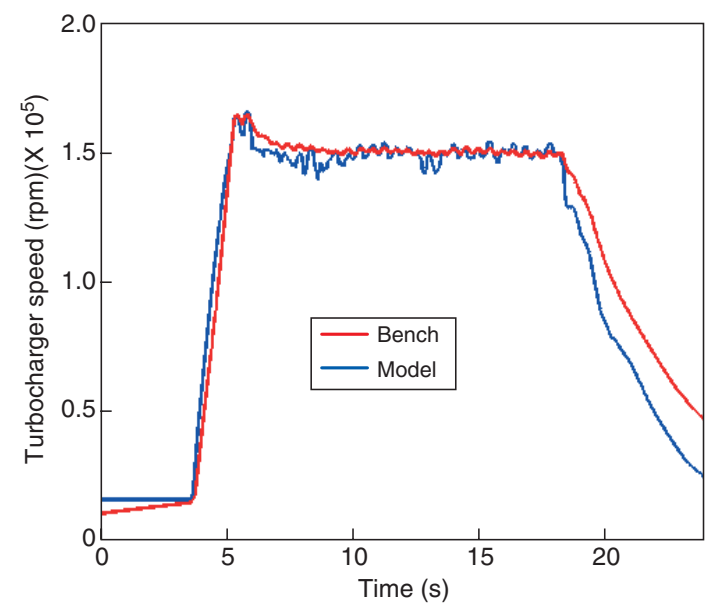

Figure 19

Turbocharger speed model/bench comparison $v s$ time during transient load@1500 rpm.

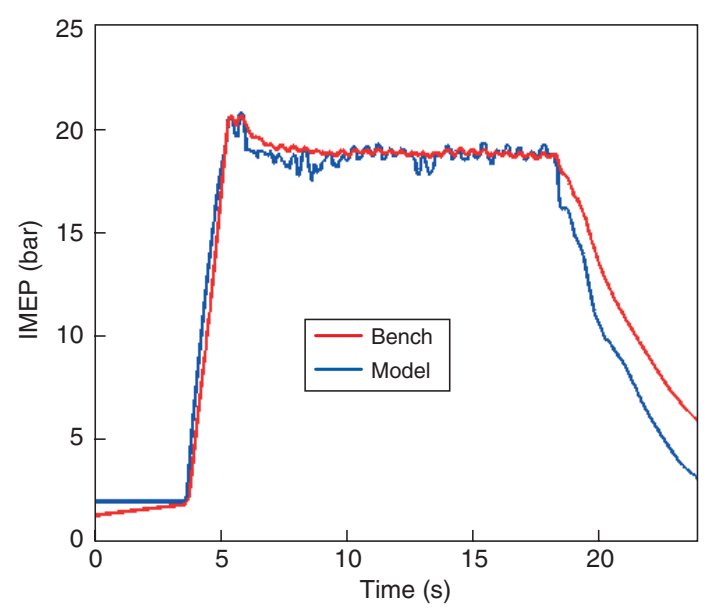

Figure 20

IMEP model/bench comparison $v s$ time during transient Load @ $1500 \mathrm{rpm}$.
IMEP. The response of transient air path to the load step is well reproduced by the virtual engine. At $4 \mathrm{~s}$, the throttle is fully opened and the waste gate is fully closed. Quickly, the intake pressure increases to atmospheric pressure. Then the turbocharger speed increases and the supercharging pressure grows. The good quality of results on intake pressure and turbocharger speed during the transient demonstrates the prediction capabilities of the model for the air path including scavenging effect and turbocharger inertia. The results presented here show a satisfactory agreement with bench data on this aspect and the model may be used to prospect strategies in order to reduce the turbo lag effect.

\section{OBSERVER DESIGN FOR ENGINE CONTROL}

Once the engine model is validated, it may be used as a support tool for engine control design.

\subsection{Model-Based Engine Control Development Cycle}

As presented in Figure 21, during the engine control development process, three main ways to use the model can be adopted. All of them may involve the same engine model which allows one to take advantage of a continuous development process and an integrated conception platform.

\subsubsection{AMESim/SIMULINK Co-Simulation}

The co-simulation environment allows two separate models to be run with two different softwares at the same time. Both solvers compute independently their respective systems and exchange information with a fixed communication step interval. Since Matlab SIMULINK is the cornerstone tool for current engine control designer, the co-simulation platform may be used in order to run the engine model on AMESim's part and the control model on SIMULINK's part. At each synchronised dialogue time, the engine model send sensor data to SIMULINK and the engine control send back actuator positions to AMESim. The engine model may be computed with the AMESim's variable timestep solver and the control model with the SIMULINK's $6^{\circ} \mathrm{CA}$ triggered management. Figure 22 presents a schematic representation of the AMESim/SIMULINK co-simulation environment.

This platform is a helpful and efficient tool to understand engine behaviour and to develop the engine observers and controllers. It allows the control design developments to be validated with the the most accurate engine model available.

\subsubsection{Engine Model Full Export to SIMULINK}

After first development and tests have been achieved for control models, the next step is to convert it to embedded version that assures robustness and real time performance. At each stage of this process, the control has to be tested as far 


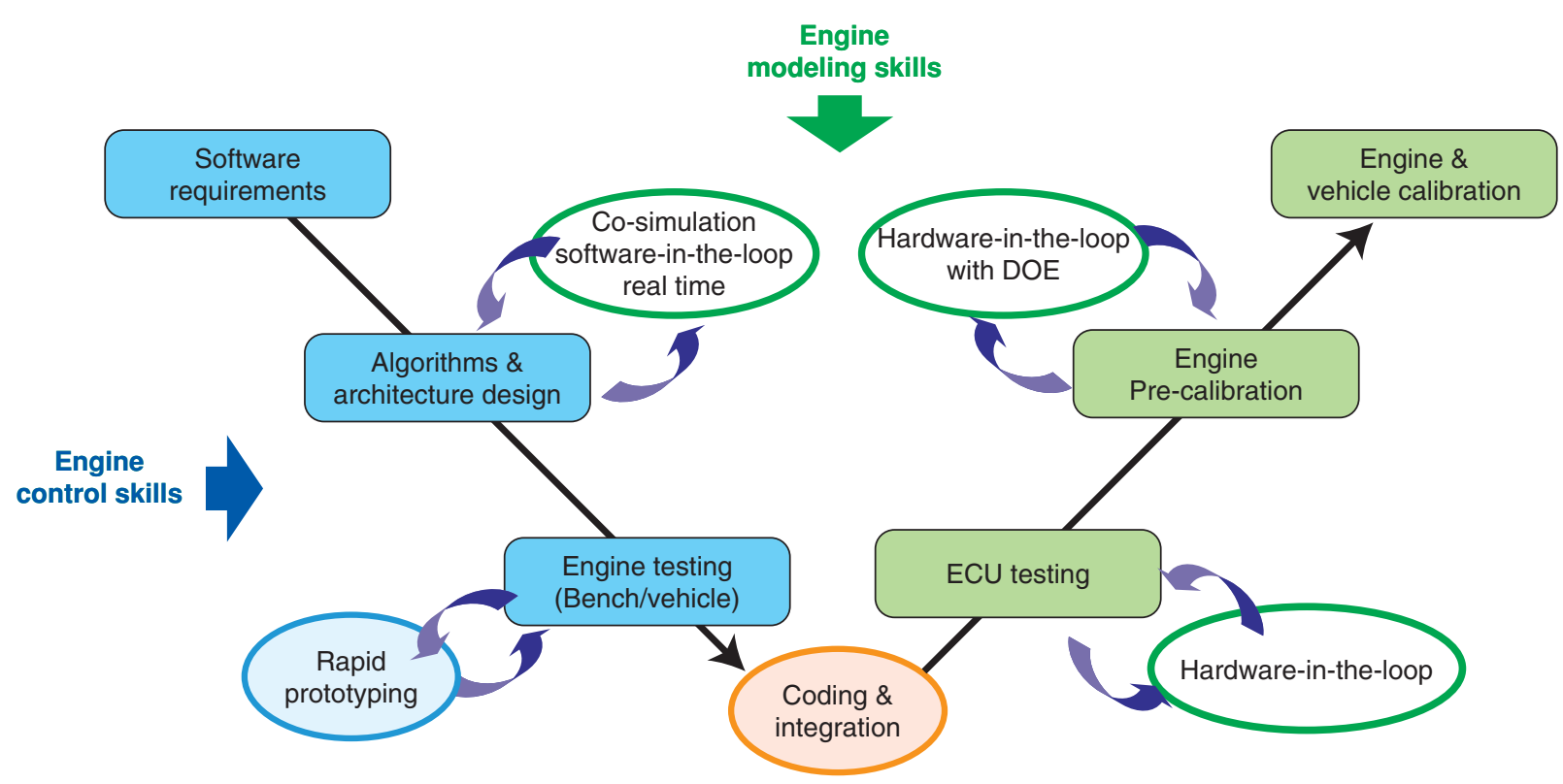

Figure 21

Model-based engine control development cycle.

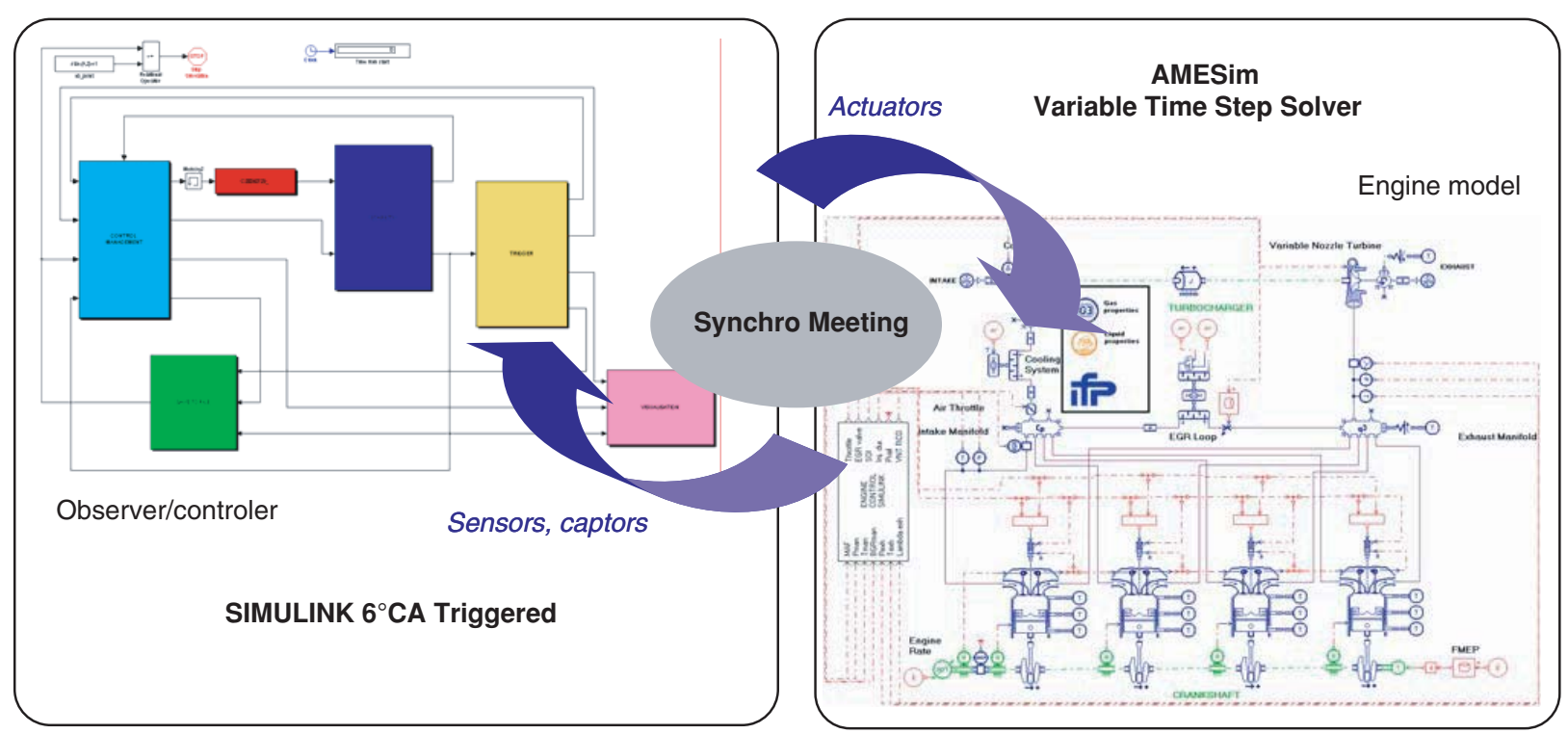

Figure 22

AMESim/SIMULINK co-simulation platform.

as possible with the engine model in order to reduce conception time and to reduce the risk of damaging prototype hardware. The engine model full export to SIMULINK is a convenient way for the control designer to avoid gaps in the development cycle. It consists in encapsulating the engine model in an S-function and in exporting it to SIMULINK. In this way, the same engine model may continue to be used for the control, computed by the SIMULINK's solver.

\subsubsection{Engine Model for Real Time Target}

The last step for the control model development before testing on the engine bench is achieved on a real time platform. Thanks to specific high-frequency modelling, the engine model may run in real time and support the control development up to real time targets such as XPC Target or dSPACE. This allows the engine model to be used upto the 
very last stages of the control design and a more robust controller to be transferred to the bench at low cost.

\subsection{In-Cylinder Mass Observer Design}

For engine control design, precise knowledge about the engine air path behaviour is extremely important. The maximum engine performance available for a given engine operating point is directly linked to the air mass trapped in the cylinder after intake valve closing (IVC), because it determines the mass of fuel that can be burnt. It is thus important to be able to predict the amount of air trapped in the cylinder in order to compute the fuel mass to be injected. Moreover, the estimation of the residual gas mass trapped in the cylinder after IVC is also a determinant factor on engine behaviour and is closely related to air path behaviour during opened valve time. Residual gas acts as a diluent, decreasing flame speed and combustion temperatures. Therefore, the residual gas fraction is especially important since it impacts NOx emissions, engine idle stability and engine performance at high residual burnt gas ratio [14].

Presently, there is no sensor available that allows incylinder masses to be determined directly and an estimation has to be made. For fixed valve timing configurations, the engine control frequently uses engine maps. The in-cylinder masses are usually mapped as a function of engine speed, intake pressure and temperature and exhaust pressure for turbocharged engines. For a variable valve timing engine, this approach is no longer possible because of the number of parameters which may influence air path behaviour and because of complex phenomena such as air cylinder bypass or burnt gas back flow.

A validated simulation model has been obtained for several steady state and transient operating set points. In order to use it for engine control development, the model has to be tested on a wide range of engine operating conditions.

\subsubsection{Wide Set Point Map Engine Model Results}

One of the main advantages of using an engine model for engine control is to perform many numerical operating set points in order to validate the controller design. In order to verify that the developed engine model is adapted to be used as a reference virtual engine for in-cylinder mass observer designs, testbed operating set points are replayed with the model using the same engine control as for the bench. These computations are performed with an AMESim/SIMULINK co-simulation platform.

Figure 23 presents the volumetric efficiencies obtained from the engine model for 100 operating set points with engine speed and load variations. The comparison with volumetric efficiency data taking into account the scavenging effect and based on bench results shows good accuracy of the numerical model.

Figure 24 presents a comparison between simulation and experiment for turbocharger speed. Good results are obtained except for lower speeds which correspond to an extrapolated part of the turbocharger maps and are less accurate.

Thanks to the accuracy obtained for in-cylinder mass prediction, the engine model has been used as a learning base for a mapped observer.

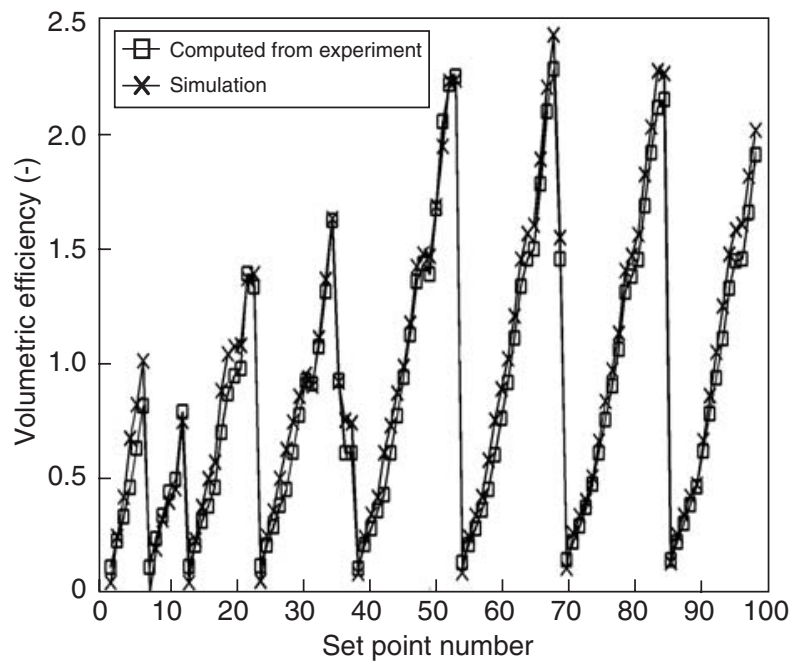

Figure 23

Loading efficiency model/calculations using experiments for 100 set points.

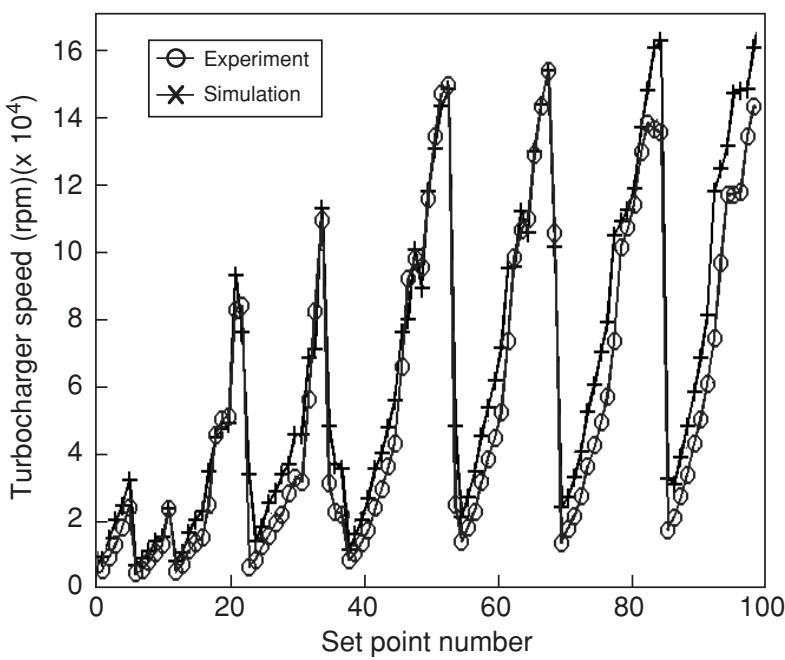

Figure 24

Turbocharger speed model/bench comparison for 100 set points. 


\subsubsection{In-Cylinder Mass Observer Development Using the Engine Model as a Learning Base}

An alternative to a model-based in-cylinder air mass observer is an observer based on neural networks. Two neural networks are built: one to model the air mass trapped into the cylinder, the second to model the burnt gas and the air bypassed from intake to exhaust.

During the working operation, two modes exist:

- The naturally aspirated mode (Pin < Patm): here the intake pressure is below the exhaust pressure, the burnt gas mass increases, the trapped air mass decreases, depending on the valve overlap and the intake pressure (Figs 25 and 26).

- The turbocharged mode (Pin > Patm): when the intake pressure becomes higher than the exhaust pressure, part of the intake air is by-passed from the intake to the exhaust manifold. The neural network models this as a negative value of the $\mathrm{BGR}_{\text {cyl }}$ which represents in this case the ratio of the intake air directly by-passed to the exhaust (Figs 27 and 28).

The engine model provides the learning base with 3500 set points. 500 set points are used to build the testing base and to validate the generalization capabilities of the neural network.

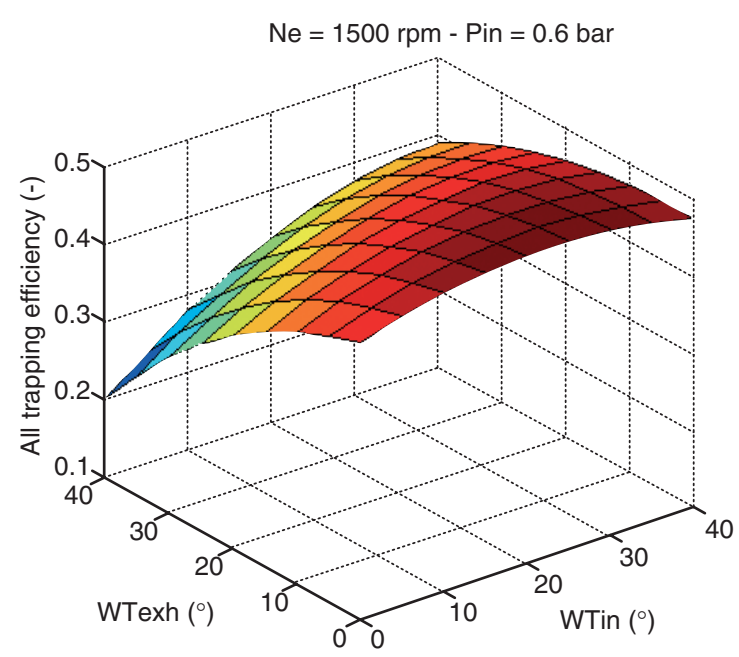

Figure 25

In-cylinder air mass observer in naturally aspirated mode for various valve timings.

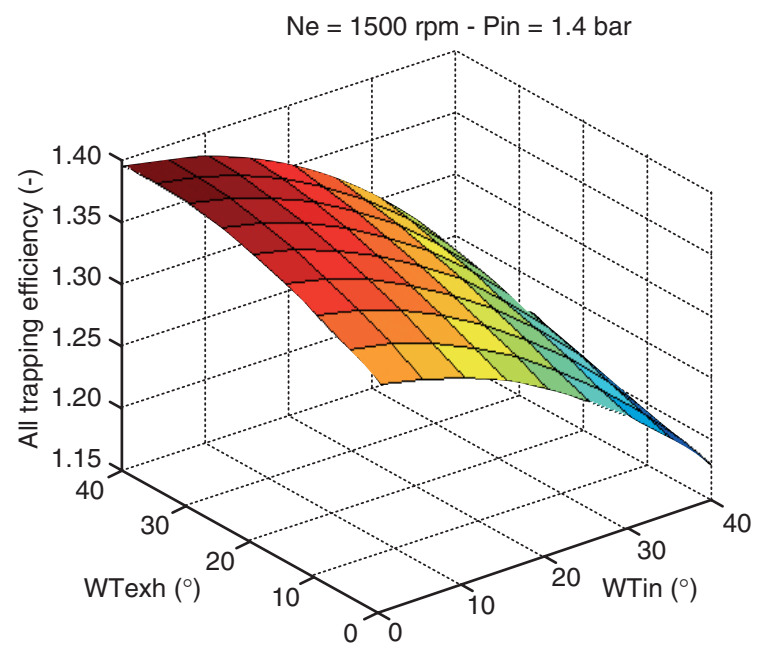

Figure 27

In-cylinder air mass observer in turbocharged mode for various valve timings.

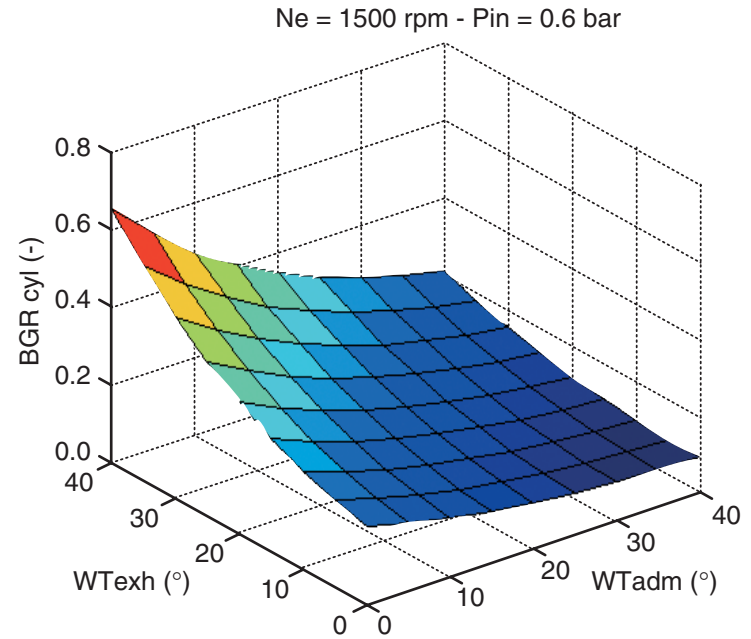

Figure 26

In-cylinder burnt gas mass observer in naturallyaspirated mode for various valve timings.

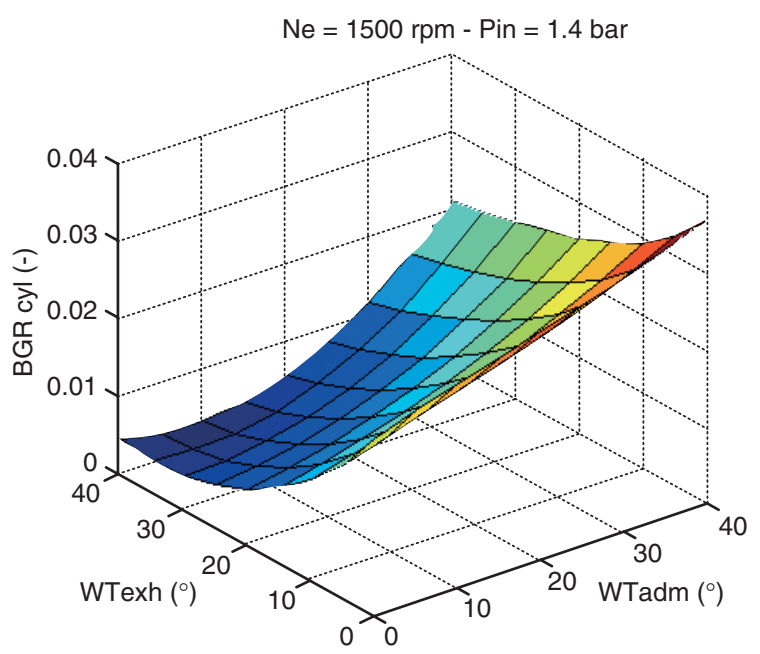

Figure 28

In-cylinder burnt gas mass in turbocharged mode for various valve timings. 


\subsubsection{Validation}

As a first step validation, the model can be used to test the developed observer during transient operating conditions. As an example of such a process, the following figures present an $8 \mathrm{~s}$ transient at $1000 \mathrm{rpm}$ which is a relevant operating condition for the in-cylinder mass estimation issue. In this case, the torque target is interpreted as air and burnt gas mass targets by the engine control. Then, according to in-cylinder mass observer results, the controller adapts the actuator positions in order to fit with the in-cylinder air and burnt gas mass targets. The air throttle and the waste gate positions are used to regulate the incylinder air mass (Fig. 29) while the VVT's positions allow the burnt gas mass trapped in the cylinders to be controlled (Fig. 30).

All the actuator trajectories are recorded during this testbed (waste-gate, air throttle, VVT's) and used to replay the test with the engine model. The results allow one to compare the air and burnt gas mass trapped in the cylinders, as estimated by the observer and by the model (Figs 31 and 32).
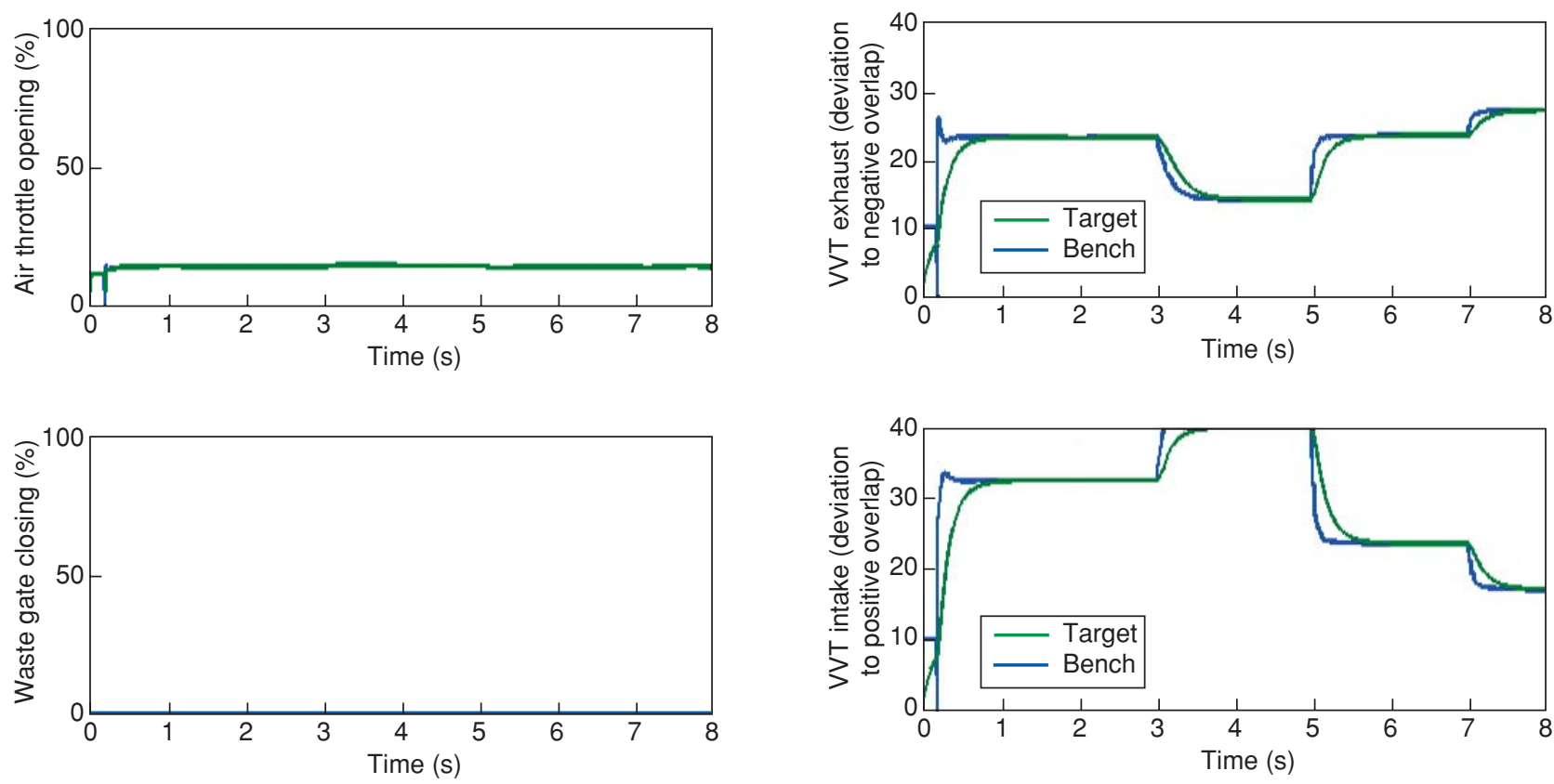

Figure 29

Figure 30

Air throttle and waste gate trajectories.

Intake/exhaust valve timing trajectories.

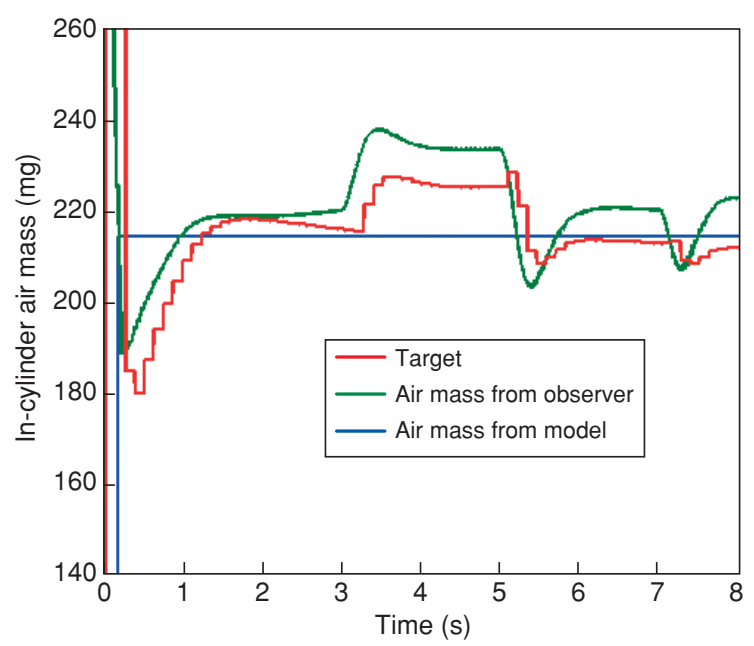

Figure 31

In-cylinder air mass observer/model comparison.

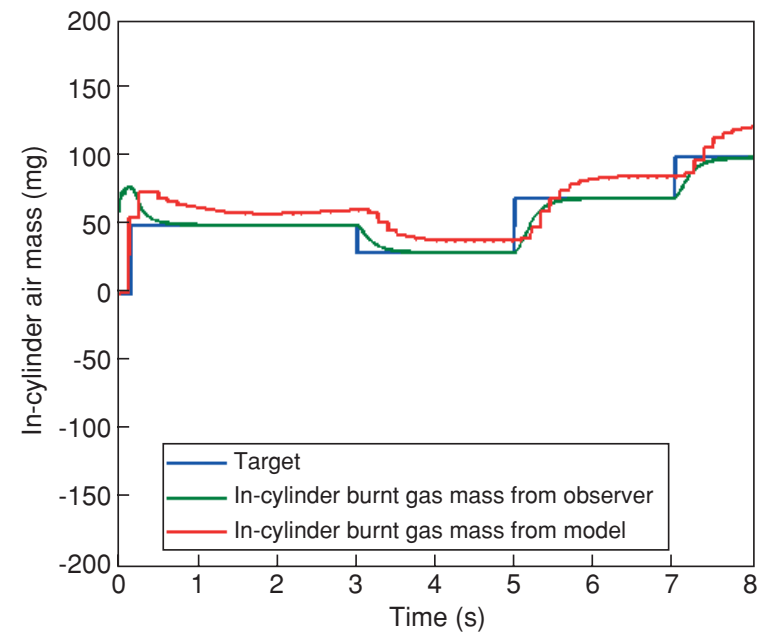

Figure 32

In-cylinder burnt gas mass observer/model comparison. 


\section{CONCLUSION}

A model of a turbocharged gasoline direct injection engine with twin-scroll turbine and variable valve timing has been developed. This engine model has been methodically validated on various steady state and transient engine operating set points thanks to bench data. The results demonstrate a good prediction capability of the model. In order to be used as a virtual engine for control development, the model has been tested on a wide range of engine set points. Results on volumetric efficiency show sufficient accuracy to allow the engine model to be used for in-cylinder mass observer design. Two different in-cylinder mass observers based on model results have been investigated and the results presented demonstrate the efficiency of the engine modelling approach in this process.

By allowing access to more engine values and limiting the test bed experiments, an engine control development process which makes full use of the engine model leads to a reduction in costs and risks of damage by providing a more robust solution when engine control is applied to the bench.

\section{ACKNOWLEDGEMENTS}

The authors want to acknowledge Guillaume Colin for his contribution and Renault SA for its collaboration.

\section{REFERENCES}

1 Lecointe, B. and Monnier, G. (2003) Downsizing of Gasoline Engine Using Turbocharging and Direct Injection. SAE Technical Paper 2003-01-0542.

2 Leduc, P., Dubar, B., Ranini, A. and Monnier, G. (2003) Downsizing of Gasoline Engine an Efficient Way to Reduce $\mathrm{CO}_{2}$ Emissions. Oil \& Gas Sc. Tech. Journal, 58.

3 Warth, M., Obrecht, P., Bertola, A. and Boulouchos, K. (2005) Predictive Phenomenological C.I. Combustion Modeling - Optimization on the Basis of Bio-Inspired Algorithms. SAE Technical Paper 2005-01-1119, Detroit, Michigan, USA.
4 Arsie, I., Di Genova, F., Pianese, C., Rizzo, G., Caraceni, A., Cioffi, P. and Flauti, G. (2005) Thermodynamic Modeling of Jet Formation and Combustion in Common Rail Multi-Jet Diesel Engines. SAE Technical Paper 2005-01-1121, Detroit, Michigan, USA.

5 Albrecht, A., Thomas, V. and Corde, G. (2005) Simulation système moteur: un élément incontournable de la chaîne de conception du contrôle moteur, Ingénieurs de l'Automobile Magazine, SIA edition, $\mathrm{n}^{\circ} 775$ bis, april.

6 Albrecht, A., Chauvin, J., Potteau, S. and Corde, G. (2005) Design of Real-Time Torque Balancing Control for Highly Premixed Combustion Engine Using a 1D Diesel Engine Model. 1st Conference on Engine Process Simulation and Supercharging, IAV, Berlin.

7 Lafossas, F., Colin, O., Le Berr, F. and Ménégazzi, P. (2005) Application of a New 1D Combustion Model to Gasoline Transient Engine Operation. SAE Technical Paper 2005-012107, Fuels \& Lubricants Meeting, Rio de Janeiro, Brazil.

8 Karnopp, D.C., Margolis, D.L. and Rosenberg, R.C. (1990) Systems Dynamics: a Unified Approach. John Wiley \& Sons, New-York, USA.

9 Chmela, F. and Orthaber, G. (1999) Rate of Heat Release Prediction for Direct Injection Diesel Engines Based on Purely Mixing Controlled Combustion. SAE Technical Paper 1999-01-0186.

10 Barba, C. and Burkhardt, C. (2000) A Phenomenological Combustion Model for Heat Release Rate Prediction in HighSpeed D.I. Diesel Engines with Common Rail Injection. SAE Technical Paper 2000-01-2933.

11 Jaine, T., Benkenida, A., Menegazzi, P. and Higelin, P. (2003) Zero Dimensional Computation of Diesel Spray Comparison with Experiments and 3D Model. 6th International Conference on Engines for Automobile.

12 Pagot, A., Monnier, G., Strobach, H., Jeckel, D. and Petitjean D. (2002) Turbocharging Application on a Gasoline Direct Injection Engine. 8. Aufladetechnische Konferenz, Dresden.

13 Leduc, P., Pagot, A., Gautrot, X. and Schmidt, O. (2004) GDI Turbocharged Engines Mono Scroll or Twin Scroll Turbine Housing? 9. Aufladetechnische Konferenz, Dresden.

14 Fox, J.W., Cheng, W.K. and Heywood, J.B. (1993) A Model for Predicting Residual Gas Fraction in Spark-Ignition Engines. SAE Technical Paper 931025, Detroit, Michigan, USA. 